\title{
BERGSON, Henri. A propósito de um artigo do Sr. Walter B. Pitkin intitulado: 'James and Bergson,
}

Trad. de José Paulo Maldonado de Souza

Mestre em Filosofia pela Universidade Federal de Pernambuco (UFPE)

josepaulomaldonado@gmail.com

RESUMO: Esta é uma tradução da resposta de Henri Bergson a um artigo de Walter B. Pitkin em que é explorado, entre outros tópicos, a interpretação que William James ofereceu - especialmente em A Pluralistic Universe - a respeito de determinados aspectos do pensamento de Bergson. Esta resposta foi publicada na seção "Discussion" de, The Journal of Philosophy, Psychology, and Scientific Methods, dois meses após a aparição, no mesmo periódico, do artigo de Pitkin. Para Bergson, as críticas de Pitkin à abordagem de James provavelmente se originam de um desentendimento quanto ao sentido atribuído à certas passagens de seus trabalhos às quais Bergson sente aqui necessidade de retornar a fim de fornecer ulteriores explicações e indicações de leitura.

Palavras-chave: Empirismo radical; intuicionismo; inteligência.

O último número de Journal of Philosophy contém um artigo notavelmente claro e preciso do Sr. Walter B. Pitkin intitulado "James and Bergson or, Who is against Intellect?"2 O Sr. Pitkin, citando e interpretando certo número de passagens de meus trabalhos, tira a conclusão de que a divergência entre as visões do Sr. Professor William James e as minhas é profunda, e que é por erro que o autor de "A Pluralistic Universe" ${ }^{3}$ teria crido que as duas doutrinas podiam prestar-se um apoio mútuo. Mais particularmente, o Sr. Pitkin ataca a interpretação que o Sr. William James deu, em seu sexto capítulo, das visões que eu expus sobre os conceitos, sobre sua origem, seu escopo e seu papel. Como eu considero, pelo contrário, a interpretação de W. James perfeitamente exata, assim como considero que o capítulo que ele de boa vontade me consagrou reproduz fielmente meu pensamento (em termos bem melhores, do que aqueles de que eu mesmo me servi), eu creio ser necessário recolocar as coisas no lugar. E eu aproveitarei a ocasião para dizer uma palavra acerca de questões conexas às que o Sr. Pitkin levanta de passagem.

O Sr. Pitkin parece ter partido da ideia que ele expõe em seu penúltimo parágrafo, segundo a qual os conceitos, tais como eu os entendo, fariam parte integrante da realidade. Estes conceitos

'BERGSON, Henri. “À propos d'un article de Mr. Walter B. Pitkin intitulé: 'James and Bergson”'. In: The Journal of Philosophy, Psychology, and Scientific Methods. v. 7, n. 14, jul., 1910, pp. 385-388.

${ }^{2}$ PITKIN, Walter B. "James and Bergson or, Who is against Intellect?". In: The Journal of Philosophy, Psychology, and Scientific Methods, v. 7, n. 9, apr., 1910, pp. 225-231.

${ }^{3}$ JAMES, William. A pluralistic universe. London, New York, Bombay and Calcuta: Longmans, Green, and co., 1909. 
seriam "grumos de uma natureza objetiva, perfeitamente real." ${ }^{4}$ E o Sr. Pitkin acrescenta, "Estes grumos ou precipitações não são, de modo algum, 'recortes' da realidade, como o Professor James constrói Bergson... O que Bergson vê e aparentemente James não é que as coisas não são reais quando imóveis e externas umas às outras, mas quando se lançam umas nas outras e interpenetramse." ${ }^{5}$ Mas, isto é, pelo contrário, o que eu não posso absolutamente admitir. Que certos conceitos sejam extraídos por nós da realidade, não me parece duvidoso; mas eu não concluo daí que eles estejam nela contidos. O aparelho fotográfico extrai de um espetáculo movente vistas imóveis: não se segue que as imobilidades façam parte do movimento. Ora, eu vejo exatamente entre a realidade e os conceitos que mais se avizinham dela a mesma relação entre a cena animada e a fotografia instantânea. ${ }^{6}$ Que seria se se considerasse todos os outros conceitos, que são bem menos ainda que aqueles, - simples notas tomadas a propósito desta realidade, e mesmo, mais frequentemente, notas tomadas sobre estas notas! Eu jamais pensei, e eu jamais disse que "o imóvel fosse tão real quanto o movente." Muito pelo contrário, eu fiz, em “A Evolução Criadora," frequentes alusões à uma tese que eu igualmente expus em outro lugar, segundo a qual toda imobilidade é relativa ou aparente: só o movimento é real, e a permanência mesma de uma forma não é mais que o desenho de um movimento. ${ }^{7}$ As maiores dificuldades filosóficas nascem precisamente ao se colocar imobilidade e movimento sobre a mesma linha e ao se lhes atribuir uma igual realidade. Desde que nos instalemos no movimento, para não mais ver na imobilidade senão uma relação ou uma negação, muitas destas dificuldades se atenuam e algumas delas se evanescem.

Eu jamais pensei tampouco que as coisas fossem mais reais "quando imóveis e externas umas às outras" do que quando "se lançam umas nas outras e interpenetram-se." Pelo contrário, eu estimo que todo despedaçamento em coisas é relativo à nossa faculdade de perceber. Nossos sentidos, apontados ao mundo material, traçam linhas de divisão que são como rotas abertas à nossa ação futura: é nossa ação eventual que nos é devolvida pela matéria, como por um espelho, quando nossos olhos percebem objetos de contornos bastante nítidos e os distinguem assim uns dos outros. ${ }^{8}$ A ciência, para fornecer pontos de apoio à nossa imaginação, leva mais longe o despedaçamento começado por nossa percepção natural. Ela prolonga o trabalho de nossos sentidos na mesma direção. Ela decomporá portanto em moléculas e átomos, ou de outra maneira qualquer, os objetos distintos que os nossos sentidos já haviam decomposto a matéria. Mas átomos,

${ }^{4}$ PITKIN, op. cit., 229.

${ }^{5}$ Ibid., 230.

6"L'Évolution Créatrice," pp. 328 sqq. Cf. p. 174 e sobretudo Introduction à la Metaphysique. (Revue de Métaphysique et de Morale, v. XI., 1903) (N.A.)

${ }^{7}$ Ver, "'L'Évolution Créatrice," capítulo IV; e Introduction à la Metaphysique, pp. 25 e seguintes. (N.A.)

8"L'Évolution Créatrice," pp. 12, 396, e sobretudo "Matière et Mémoire," p. 233 e p. 218 sqq. Ver igualmente o cap. I. deste último livro. (N.A.) 
moléculas, centros de força, etc., não me parecem ter mais realidade absoluta que os "objetos distintos" eles mesmos. ${ }^{9}$

Isto não quer dizer que a percepção e a ciência movam-se no irreal. O Sr. Pitkin citou algumas passagens de meus trabalhos onde eu digo que nossa inteligência "está afinada com a matéria" e que nossa física atinge de direito, senão de fato, a realidade absoluta. Ele poderia ter citado ainda outras. Mas estas passagens não têm o sentido que o Sr. Pitkin lhes atribui: - e esta bem poderia ser a origem do mal-entendido. Há com efeito duas coisas a se distinguir nos dados dos sentidos: a percepção dos objetos, nitidamente recortados no espaço, e a das qualidades, que formam como que continuidades sensíveis. E há também duas coisas a se distinguir na ciência: de um lado os conceitos e de outro as relações matemáticas ou leis.

No que concerne primeiramente aos dados dos sentidos, eu tentei estabelecer que, enquanto o despedaçamento da matéria em coisas ou objetos é inteiramente relativa às nossas necessidades, pelo contrário, a percepção das qualidades sensíveis é muito mais independente da necessidade e apresenta portanto uma realidade objetiva superior. Sem dúvidas, a percepção destas qualidades sensíveis não é a mesma em todos os seres conscientes; ela deve depender do grau de complicação e de perfeição dos órgãos dos sentidos: quanto mais se eleva, mais a qualidade é concentrada; quanto mais descende, mais é diluída. Mas é precisamente por isso que entrevemos, no limite, lá embaixo, uma diluição extrema que seria a materialidade mesma. À esta materialidade, que é mais quantidade que qualidade, eu atribuo uma realidade "absoluta" no mesmo sentido em que se pode dizer que as milhares e milhares de células de um tecido, percebidas em microscópio, são uma realidade absoluta em relação ao aspecto simplificado que o tecido apresenta a olho nu. Isto não é o "horripilante absoluto" ${ }^{10}$ do qual o Sr. Pitkin evoca o espectro, um absoluto estrangeiro à nossa representação ou ainda simplesmente distinta daquela. É um absoluto percebido em miniatura. Nós tomamos estas excitações elementares, constitutivas da matéria, na qualidade sensível em que se contraem, assim como tomamos as palpitações de nosso coração no sentimento geral que temos de viver. ${ }^{11}$

É neste sentido que o progresso de nossa física me parece reaproximar-se da matéria mesma, em sua essência “absoluta”. Há, com efeito, duas partes a distinguir em nossa ciência: uma coisa é o conceito, outra coisa a lei ou relação matemática. Os conceitos ajudam a ciência, mas jamais são para ela mais do que esquemas provisórios; o objetivo último da ciência é descobrir as relações matemáticas e mesmo resolver a matéria em relações deste gênero. Ora, eu estimo que esta geometria seja o fundo mesmo da matéria, que ela seja imanente à percepção que nós temos. Nossa

\footnotetext{
9"Matière et Mémoire", p. 221. (N.A.)

${ }^{10}$ PITKIN, op. cit., p. 228.

${ }^{11}$ Cf. "Matière et Mémoire," p. 232 em particular. (N.A.)
} 
inteligência, que vai naturalmente à geometria, está afinada com a matéria. Eis porquê eu disse que a inteligência, se inábil para compreender o espirito, se incompetente no domínio da vida (que é o que há de positivo na realidade), está à vontade no domínio da matéria inerte. ${ }^{12}$

Fluxo posto sobre um fluxo, nossa consciência se conhece a si mesma em sua essência, e conhece também em sua essência a matéria que ela toca, com a qual coincide parcialmente. Eu não me represento portanto nulamente "a vida como experiência transcendente,"13 nem a realidade absoluta como situada "além da mais penetrante intuição." ${ }^{14}$ A vida transcende a inteligência, mas não a experiência; e aquela captura-se a si mesma absolutamente em uma intuição que, incompleta de fato, pode completar-se indefinidamente.

Estas últimas explicações eram necessárias, para indicar o sentido exato de certas passagens de meus trabalhos que o Sr. Pitkin citou. Eu não sei se as visões desenvolvidas naquelas diversas passagens seriam aceitas tais e quais pelo Sr. William James: de minha parte, não vejo nada de incompatível com o conjunto de sua doutrina, nada que exceda os limites de um empirismo radical. Mas esta não é a questão. O Sr. William James não quis expor, e não declarou levar em conta, senão certa teoria dos conceitos e do lugar que a inteligência ocupa no conjunto da realidade. Sobre tudo isso ele disse exatamente o que eu penso. Eu gostaria apenas de tê-lo dito tão bem.

H. Bergson

Paris, 18 de maio, 1910.

\footnotetext{
${ }^{12} \mathrm{Eu}$ expliquei em outra parte como esta matéria é, com relação ao espírito, qualquer coisa de negativo. (“L'Évolution Créatrice," pp. 218 sqq.) (N.A.)

${ }^{13}$ PITKIN, op. cit., p. 226.

${ }^{14}$ Ibid., p. 226.
} 